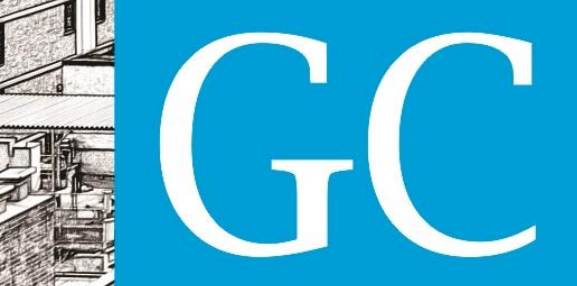

Revista Nacional de

Gerenciamento de Cidades

National Joumal of Cities Management

\title{
Vila Dignidade de Araraquara na percepção de seus moradores: habitação amiga do idoso?
}

Vila Dignidade de Araraquara in the perception of its residents: habitation friendly to the elderly?

Vila Dignidade de Araraquara en la percepción de sus habitantes: vivienda amiga del anciano?

Nayara Mendes Silva Mestranda do Programa de Pós-Graduação em Gerontologia, UFSCar, Brasil nayara.mm@live.com

Filipe Augusto Portes Mestrando do Programa de Pós-Graduação em Gerontologia, UFSCar, Brasil fi.augusto.portes@gmail.com

Luzia Cristina Antoniossi Monteiro Doutora em Engenharia Urbana e docente do Programa de Pós-Graduação em Gerontologia, UFSCar, Brasil Cristinaantoniossi4@gmail.com 


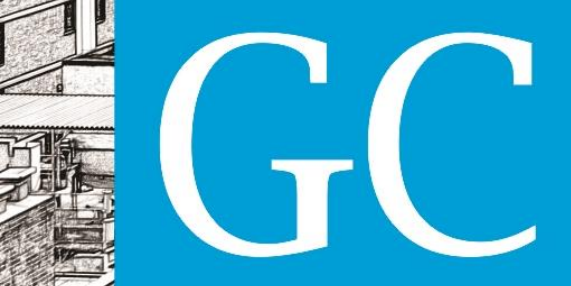

Revista Nacional de

\section{RESUMO}

Dentre os desafios inerentes do envelhecimento populacional, destaca-se a carência de políticas públicas habitacionais para idosos de baixa renda. Atento à questão, o Estado de São Paulo, por meio da Companhia de Desenvolvimento Habitacional e Urbano (CDHU), criou o Programa Vila Dignidade, equipamento público destinado para a população idosa em situação de vulnerabilidade social, que visa fornecer moradias adequadas por incorporar os princípios do Desenho Universal. Por se tratar de uma política habitacional recente, cuja literatura ainda é escassa, o presente artigo objetivou analisar a percepção dos moradores sobre as condições de moradia do Vila Dignidade de Araraquara - SP. Trata-se de um estudo quanti-qualitativo, recorte de uma pesquisa de mestrado apoiada pela FAPESP (processo no 2017/07875-3), cuja coleta de dados se desenvolveu com a oitiva dos moradores. Foram entrevistadas 16 pessoas, que destacaram, enquanto ponto positivo a isenção de aluguel, e criticaram as condições insatisfatórias dos pisos e problemas ocasionados pelas chuvas que alagam as casas, o que evidencia, do ponto de vista dos participantes, a importância da moradia gratuita e acessível. Conclui-se que o Vila Dignidade de Araraquara apresenta aspectos que comprometem a segurança e o conforto dos idosos, contrariando princípios norteadores do próprio programa. Ainda que se constate fatores a serem aprimorados, o condomínio consiste em avanço à consecução da moradia, pois sua implementação viabiliza o acesso de idosos de baixa renda a este direito fundamental.

PALAVRAS-CHAVE: Habitação para pessoa idosa. Moradia adequada. Políticas Públicas Habitacionais.

\section{ABSTRACT}

Among the inherent challenges of population aging is the lack of public housing policies for low-income elderly people. The State of São Paulo, through the Housing and Urban Development Company (CDHU), created the Vila Dignidade Program, a public facility designed for the elderly population in situations of social vulnerability, which aims to provide adequate housing by principles of Universal Design. It consists of a recent housing policy, whose literature is still scarce. In this sense, the present article aimed to analyze the perception of the residents about the housing conditions of Vila Dignidade de Araraquara - SP. This is a quanti-qualitative study, a cut of a masters study supported by FAPESP (process no 2017 / 07875-3), whose data collection was developed with the residents' interview. 16 people were interviewed, who highlighted, as a positive the rent exemption, and criticized the conditions of the floors and problems caused by the rains that flood the houses, which shows, from the point of view of the participants, the importance of free and physically accessible housing. It is concluded that Vila Dignidade de Araraquara presents aspects that compromise the safety and comfort of the elderly, contrary to the guiding principles of the program itself. Although there are factors to be improved, the condominium advancing the achievement of the dwelling, since its implementation facilitates the access of low-income elderly people to fundamental rights. Listening to these people's perceptions is important in order to guide the planning of public policies that are coherent with their needs. PALAVRAS-CHAVE: Housing for elderly person. Adequate housing. Housing Public Policies.

\section{RESUMEN}

Entre los desafíos inherentes al envejecimiento de la población está la falta de políticas públicas de vivienda para ancianos de bajos ingresos. El Estado de São Paulo, por medio de la Compañía de Desarrollo Habitacional y Urbano (CDHU), creó el Programa Vila Dignidad, un servicio público destinado a la población anciana en situación de vulnerabilidad social, que busca proporcionar una vivienda adecuada por los principios del Dibujo Universal. Consiste en una política habitacional reciente, cuya literatura todavía es escasa. En este sentido, el presente artículo objetivó analizar la percepción de los habitantes sobre las condiciones habitacionales de la Villa Dignidad de Araraquara - SP. Se trata de un estudio cuanti-cualitativo, parte de un estudio de maestría apoyado por la FAPESP (proceso no 2017 / 07875-3), cuya recolección de datos fue desarrollada con la entrevista de los habitantes. Se entrevistaron a 16 personas, que destacaron, como positiva la exención del alquiler, y criticaron las condiciones de los pisos y los problemas causados por las lluvias que inundan las casas, lo que evidencia, desde el punto de vista de los participantes, la importancia de la libre y vivienda físicamente accesible. Se concluye que la Villa Dignidad de Araraquara presenta aspectos que comprometen la seguridad y el confort de los ancianos, contrariando los principios orientadores del propio programa. Aunque existen factores a ser perfeccionados, el condominio promueve el avance de la vivienda, ya que su implantación facilita el acceso de ancianos de bajos ingresos a los derechos fundamentales. Escuchar las percepciones de esas personas es importante para orientar la planificación de políticas públicas coherentes con sus necesidades.

PALAVRAS-CHAVE: Vivienda para personas mayores. Vivienda adecuada. Políticas Públicas Habitacionales. 


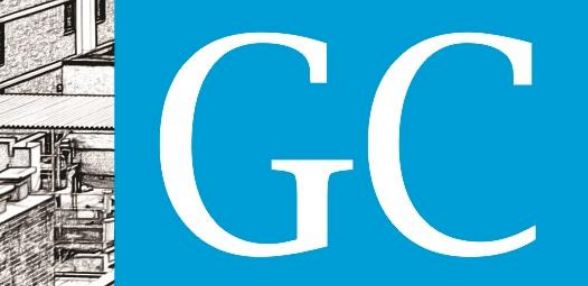

Revista Nacional de

moradores (centro de convivência) que incorpora os princípios do Desenho Universal, permitindo a integração dos idosos à rede de suporte social do município.

Enquanto procedimentos para a coleta de dados, utilizou-se o Protocolo de Vancouver, mesmo questionário utilizado na Estratégia Cidade Amiga do Idoso da OMS (2007), que busca captar a percepção dos participantes sobre os oito itens que compõem uma cidade amiga do idoso, dentre os quais, está a moradia.

Nesse sentido, descrever-se-á neste trabalho os resultados referentes à oitiva dos moradores acerca da percepção deles quanto às casas. Especificamente: custos, conforto, proximidade à serviços/mobilidade e independência no lar (itens que contemplam o eixo moradia do Protocolo de Vancouver). Para análise dos dados, a fundamentação utilizada foram os princípios de análise de conteúdo e a literatura científica sobre o tema (BARDIN, 2016).

\section{RESULTADOS}

Das 20 casas do Vila Dignidade - Araraquara, somente duas estavam vazias, e em cada unidade residia apenas uma pessoa. Deste modo, dos 18 moradores do local, foram entrevistados 16.

Do total de participantes, dez declararam satisfação quanto aos custos de suas residências, já que, por se tratar de política pública habitacional, seus moradores não pagam aluguel. Nesse sentido, alguns disseram usar seus rendimentos para a aquisição de mantimentos e outras despesas.

"Não pago nada, mas também tento economizar... não durmo com a luz acesa pra não dar gasto para o governo (...) uso meu dinheiro para comprar coisas pra mim".

Se por um lado há satisfação de alguns quanto aos custos de manutenção da casa, por outro, houveram pessoas que ressaltaram a necessidade de dispêndio para realizar reformas. Os moradores reconheceram a necessidade de intervenções, porém alegaram não arcar com tais despesas, seja pela falta de recursos, pela recomendação de não alterar os padrões do local, ou mesmo pela espera dos gestores em se encarregarem da realização destas modificações.

"Os pisos da casa estão estourando, não são antiderrapantes. Quando chove molha boa parte da casa, a chuva entra pelas duas portas. Tem que ficar fechando a casa, há poucas rachaduras e a pintura é ruim com paredes descascadas".

Este relato demonstra o descontentamento de uma entrevistada que descreve as condições dos dois principais problemas referidos pelos moradores: a chuva que adentra as casas e as condições dos pisos.

Cinco idosos referiram os problemas advindos das chuvas, dentre os quais se destaca à vazão de água para dentro das moradias. Para resolver este problema, os entrevistados solicitaram intervenções como instalação de telhados na entrada das casas, assim como a construção de degraus nas portas das residências para conter a água.

"Quando chove, molha a minha casa, fica parecendo uma lagoa." 
Os idosos também se referiram a situação crítica dos pisos, alguns estourados e todos escorregadios, situação que se agrava nos dias chuvosos. Nesse sentido, a sugestão dos moradores é de que os pisos sejam trocados por antiderrapantes para minimizar o número de quedas já ocorridas com muitas pessoas.

Outro fator apontado faz menção à largura insatisfatória do portão do condomínio. Este é o único meio de entrada no Vila Dignidade, porém, volta-se apenas para a passagem de pedestres. Sendo assim, foi evidenciada a necessidade de alargamento para possibilitar o acesso de veículos, como uma ambulância em casos de urgência.

As principais críticas feitas pelos moradores do Vila Dignidade podem ser visualizadas na próxima tabela:

Tabela 1: Itens insatisfatórios nas moradias do Vila Dignidade

\begin{tabular}{cc}
\hline Itens insatisfatórios & No de relatos \\
\hline Trincas & 1 \\
\hline Piso insatisfatório (estoura) & 5 \\
Piso escorregadio & 4 \\
Água da chuva entra em casa & 9 \\
Fiação elétrica / iluminação & 2 \\
Pia da cozinha caindo & 1 \\
Infiltração & 1 \\
\hline Total & $\mathbf{2 3}$ \\
\hline Elaboração: OS AUTORES, 2018.
\end{tabular}

Diante de tantas críticas, os participantes do Vila Dignidade discorreram sobre algumas modificações necessárias no condomínio para minimizá-las, conforme demonstra a tabela a seguir.

Tabela 2: sugestões de melhorias feitas pelos moradores

\begin{tabular}{cc}
\hline Solicitações & № de relatos \\
\hline Colocação de pisos antiderrapantes & 2 \\
Aumentar comprimento do portão principal & 2 \\
Barreiras para conter água da chuva & 5 \\
Colocação de box no banheiro & 1 \\
\hline Total & $\mathbf{1 0}$ \\
\hline
\end{tabular}

Elaboração: OS AUTORES, 2018.

Mesmo em face de tantos pedidos e queixas, é expressivo o número de moradores que relataram sentirem-se confortáveis em casa. Opinião compartilhada por treze participantes..

Quanto à segurança percebida, seis idosos informaram sentir-se seguros no condomínio, ao passo que cinco moradores alegaram insegurança, dois destes, justificaram tal opinião ao referir 


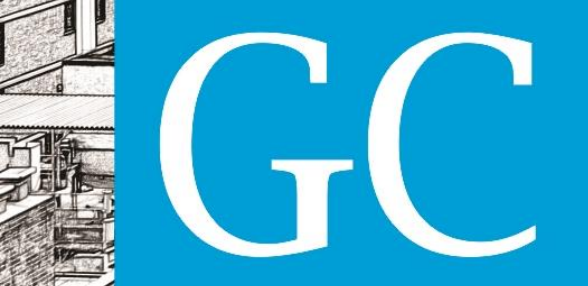

Revista Nacional de

A moradia é um local carregado de significados e é onde as pessoas idosas passam a maior parte do tempo, nesse sentido, as condições físicas e subjetivas exercem grande impacto na qualidade de vida dessa população (PASTERNAK, 2016).

Considerando as restrições de renda e novas estruturas familiares que interferem nas formas de suporte à pessoa idosa, o Estado se destaca no dever de implementar políticas sociais que viabilizem condições de envelhecimento favoráveis. Deste modo, além da oferta por moradia, é fundamental que as unidades habitacionais sejam apropriadas ao público alvo de tais políticas, numa perspectiva de que sejam adequadas (MARTIN et al,2012).

Nesse sentido, faz-se imprescindível considerar a amplitude de fatores que compõem a moradia adequada. O Comentário no 4 do Comitê sobre os Direitos Econômicos, Sociais e Culturais, estabelece alguns critérios que contemplam uma moradia adequada: Segurança da posse; Disponibilidade de serviços, materiais, instalações e infraestrutura; Economicidade; Habitabilidade; Acessibilidade; Localização e Adequação cultural (UNITED NATIONS, 1991).

Já o Centro das Nações Unidas para os Assentamentos Humanos/ HABITAT, utiliza a seguinte definição:

\footnotetext{
moradia adequada é mais que um teto sobre a cabeça. Também significa privacidade adequada; espaço adequado; acessibilidade física; segurança adequada; segurança da posse; estabilidade estrutural e durabilidade; iluminação, aquecimento e ventilação adequados; infraestrutura básica; qualidade ambiental, bem como a localização adequada... (MORAIS, 2002, p-112-113).
}

Em face à abrangência de aspectos que compõem a moradia adequada, espera-se que gestores de tais políticas habitacionais, considerem o maior número de aspectos que a compõem, levando em consideração à subjetividade e heterogeneidade do público alvo, compreendendo suas especificidades ao invés de atribuí-los estereótipos na produção de políticas que por muitas vezes podem ser ineficientes (PFUTZENREUTE et al., 2015).

\section{CONCLUSÃO}

Tão importante quanto garantir moradias, é torná-las eficientes. Neste contexto, faz-se imprescindível considerar a aplicação de parâmetros de acessibilidade, como o Desenho Universal, reflete na autonomia e independência dos indivíduos nos ambientes independentemente das suas características e condições físicas.

Mesmo com a identificação de fatores a serem aprimorados, o Vila Dignidade caracteriza-se enquanto verdadeiro avanço à consecução da moradia adequada, pois a sua implementação viabiliza o acesso ao direito fundamental da habitação para pessoas idosas hipossuficientes. Ainda, estudos como o descrito no presente trabalho, favorecem a autoavaliação do município no que tange à verificação da efetividade das políticas implementadas.

De acordo com a OMS, a Estratégia Cidade Amiga do Idoso é um importante instrumento para que uma cidade possa mapear e autoavaliar sua evolução. Deste modo, faz-se pertinente apontar que o desenvolvimento de ações do poder público consiste em uma evolução, pois se 


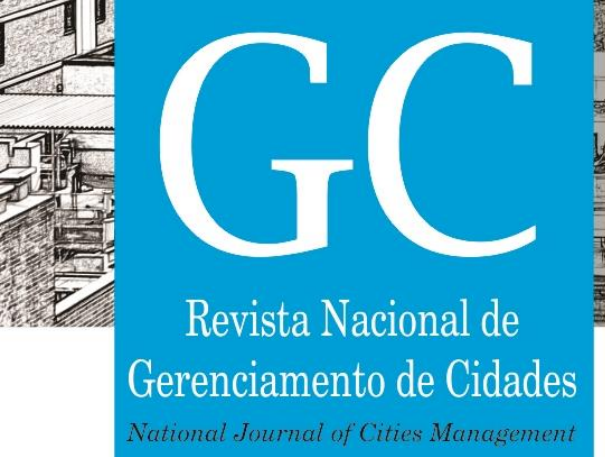

SÃO PAULO (Estado). Secretaria da habitação. Programa Vila Dignidade. Disponível em: $<$ http://www.habitacao.sp.gov.br/programas-habitacionais/programas-secretaria-dahabitacao/programa-vila-dignidade.asp $>$. Acesso em mar. 2011.

SÃO PAULO, Governo do Estado de. Decreto № 53.485, de 26 De Setembro de 2008.

Institui, no âmbito da Administração Centralizada e Descentralizada do Estado de São Paulo, a política de implantação do conceito de desenho universal na produção de habitação de interesse social Disponível em: < http://www.al.sp.gov.br/repositorio/legislacao/decreto/2008/decreto53485-26.09.2008.html > Acesso em agosto de 2018.

SÃO PAULO, Assembleia Legislativa do Estado de. Decreto no 54.285, de 29 de abril de 2009. Disponível em: <http://www.al.sp.gov.br/repositorio/legislacao/decreto/2009/decreto-5428529.04.2009.html >. Acesso em agosto de 2016.

SCHUSSEL, Z. das G. L. (2012, dezembro). Os idosos e a habitação. Revista Kairós Gerontologia, 15(8), p53-56. Online ISSN 2176-901X. Print ISSN 1516-2567. São Paulo (SP), Brasil.

STONE, Robyn I. The housing challenges of low-income older adults and the role of federal policy. Journal of aging \& social policy, p. 1-17, 2018.

UNITED NATIONS. (1991) Committe on Economical, Social and Cultural Rights. General Comment № 04: The Right To Adequate Housing (Art. 11, Para. 1). Geneva. Disponível em: <http://www.unhchr.ch/tbs/doc.nsf/0/469f4d91a9378221c12563ed0053547e>. 